\title{
Hepatitis B Screening Before Biologic or Targeted Synthetic Disease-modifying Antirheumatic Drug Therapy: Many Roads to Improvement
}

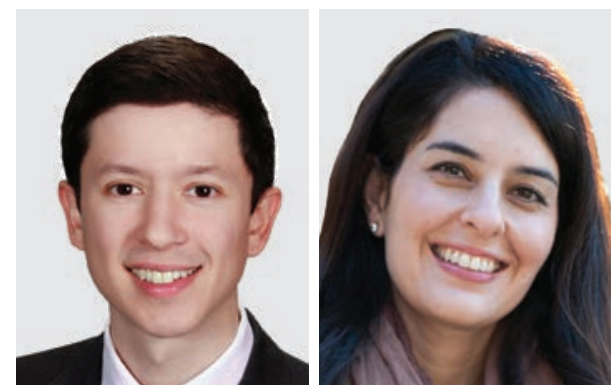

\author{
Alfredo Aguirre ${ }^{1}$ (I) and Jinoos Yazdany ${ }^{1}$ (D)
}

Biologic and targeted synthetic disease-modifying antirheumatic drugs ( $\mathrm{b} / \mathrm{tsDMARDs}$ ) have long been recognized to cause hepatitis $B$ virus $(\mathrm{HBV})$ reactivation in individuals chronically infected with or previously exposed to HBV. ${ }^{1}$ Despite this knowledge, many patients treated with $\mathrm{b} / \mathrm{tsDMARD}$ s experience $\mathrm{HBV}$ reactivation each year because of inconsistent screening. ${ }^{2}$ Because of its largely asymptomatic clinical expression and low testing rates, the HBV burden in patients with rheumatic diseases is difficult to determine. However, $\mathrm{HBV}$ is likely more common than we may suspect, based on studies conducted in the general population. In the US, an estimated 875,000 persons are living with chronic $\mathrm{HBV}$ (HBsAg-positive), although prior or resolved $\mathrm{HBV}$ ( $\mathrm{HBcAb}$-positive, $\mathrm{HBs} A g$-negative, with or without $\mathrm{HBs} \mathrm{Ab}$ ) is much more common, affecting up to 11 million persons. ${ }^{3,4}$ Most of these individuals are either undiagnosed or unaware of their HBV status, as is the case with up to

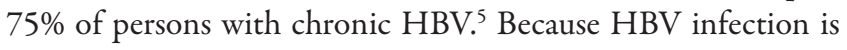
common and underdiagnosed, and immunosuppression with $\mathrm{b} / \mathrm{ts}$ DMARDs can lead to HBV reactivation with deleterious consequences ranging from HBV DNA elevations to fatal liver failure, ${ }^{1} \mathrm{HBV}$ screening prior to $\mathrm{b} / \mathrm{tsDMARD}$ initiation is a relatively simple, low-cost step critical to delivering high-quality rheumatologic care.

The article by Mohareb et al in this issue of The Journal of Rheumatology is a timely addition to research on drug safety of newer $\mathrm{b} / \mathrm{tsDMARD}$ in patients with rheumatic diseases,

AA and JY are supported by the National Institute of Arthritis and Musculoskeletal and Skin Diseases of the National Institutes of Health under award number 1T32AR079068-01 (AA) and K24 AR074534 (JY).

${ }^{1}$ A. Aguirre, MD, Clinical Fellow, J. Yazdany, MD, MPH, Professor, Division of Rheumatology, University of California, San Francisco, California, USA.

The authors declare no conflicts of interest relevant to this article.

Address correspondence to Dr. A. Aguirre, Division of Rheumatology,

University of California, San Francisco, 4150 Clement St. (111R), San

Francisco, CA 94121, USA. Email: alfredo.aguirre@ucsf.edu. exploring deficiencies in HBV screening practices in individuals initiating tocilizumab (TCZ) or tofacitinib (TOF) in an integrated health network. ${ }^{6}$ Both agents are increasingly recognized to carry a risk of $\mathrm{HBV}$ reactivation ${ }^{7,8}$ and despite their growing use in rheumatology, little is known about practices to ensure their safe administration. This study found that HBV screening in new users of TCZ or TOF was remarkably low, with fewer than one-third having been tested with the full complement of $\mathrm{HBsAg}$, total $\mathrm{HBcAb}$, and $\mathrm{HBsAb}$ tests. ${ }^{6}$ Surprisingly, the investigators also found that some $\mathrm{HBV}$ testing was incorrect or inappropriate. For example, more than one-fifth of subjects without evidence of active infection had $\mathrm{HBeAg}, \mathrm{HBcAb} \operatorname{IgM}$, or HBV DNA testing, a finding that highlights the need to target interventions around $\mathrm{HBV}$ testing, as well as reduce unnecessary healthcare spending.

In this study, individuals of non-White race were tested more frequently than White users of TCZ or TOF, possibly reflecting clinicians' awareness of the epidemiology of HBV infection. ${ }^{6}$ However, the prevalence of $\mathrm{HBV}$ exposure in the general population is high enough to warrant universal screening before immunosuppression. In the US, an estimated $0.34 \%$ and $4.3 \%$ of the population have chronic and prior or resolved HBV, respectively. This can vary dramatically depending on the patient population: for instance, the prevalence of chronic and prior or resolved $\mathrm{HBV}$ is $2.7 \%$ and $21.5 \%$ in Asians, and $0.6 \%$ and $8.9 \%$ in non-Hispanic Blacks, respectively. ${ }^{5}$ Given that many rheumatic diseases disproportionately affect non-White populations, it is critical to develop standardized protocols to screen all patients initiating immunosuppression.

The results of Mohareb et $\mathrm{al}^{6}$ are notable in the context of published guidelines on HBV screening prior to immunosuppression and the literature on $\mathrm{HBV}$ reactivation, but they are not altogether surprising. There is ample evidence of widespread deficiencies in HBV screening prior to immunosuppression, and in the national Rheumatology Informatics System for

\section{See HBV screening before immunosuppression, page 104}


Effectiveness (RISE) registry of practices in the US, less than one-third of patients had complete HBV testing (defined in this paper as HBsAg and $\mathrm{HBcAb}$ ). ${ }^{9}$ The study by Mohareb et al provides a powerful motivation to enhance procedures to reduce patient safety risks associated with b/tsDMARDs. ${ }^{6}$

\section{Universal screening with appropriate $H B V$ testing}

The study by Mohareb et al adds to the growing literature supporting universal HBV screening for all new users of b/tsDMARDs. ${ }^{6}$ In the absence of clear guidelines or safety checks for hepatitis testing, there is evidence that clinicians are making individual, patient-specific decisions about who should be tested for HBV. These assessments depend on a range of factors, including established and perceived risk factors for HBV. However, clinicians consistently overlook or underplay the most important risk factor for acquiring $\mathrm{HBV}$ and developing chronic infection: birth in a high-prevalence region. ${ }^{10}$ Many studies have revealed suboptimal knowledge of HBV risk factors in a variety of medical professionals, as well as a tendency to place more importance on certain patient characteristics when assessing HBV risk, such as injection drug use. ${ }^{11,12,13}$

Existing American College of Rheumatology (ACR) guidelines are likely contributing to the uneven standard of care and need updating. The 2021 ACR rheumatoid arthritis (RA) guidelines acknowledge patients with $\mathrm{HBV}$ as a special patient population of interest and specify recommendations for viral load monitoring and antiviral treatment in those with chronic and prior or resolved HBV. ${ }^{14}$ These recommendations imply systematic HBV screening by clinicians, although this is not stated explicitly, and prior RA guidelines have instead advised a risk-based strategy of HBV testing. ${ }^{15}$ This is in contrast with other national guidelines, such as those issued by the Centers for Disease Control and Prevention and the American Association for the Study of Liver Diseases, which advocate universal HBV screening prior to any immunosuppressive agent. ${ }^{16,17}$

Updated recommendations on universal screening will need to be explicit about when to screen for HBV. In the study by Mohareb et $\mathrm{al},{ }^{6}$ a surprising finding was that complete HBV screening was not associated with prior conventional synthetic DMARD or bDMARD use, suggesting that HBV screening is suboptimal across multiple classes of immunosuppression. Since there is clear evidence of HBV reactivation with almost every form of immunosuppression, including moderate-to-high doses of steroids and b/tsDMARDs, universal screening would likely be more practical and less confusing if the scope of the recommendation included all immunosuppressive medications, including b/tsDMARDs, despite small-to-modest differences in $\mathrm{HBV}$ risk from agent to agent. Current ACR guidelines tend to be disease-specific, but disseminating drug safety recommendations across rheumatic diseases may be beneficial, as in a recent DMARD safety guideline for patients with inflammatory arthritis in the UK. ${ }^{18}$ An added benefit of universal screening is the promotion of drug safety with newly approved $\mathrm{b} / \mathrm{ts}$ DMARDs, many of which were investigated in trials that excluded patients with HBV infection. This can safeguard our patients while observational data is collected on HBV reactivation risks associated with newly approved medications.

Clear guidelines on universal screening will be most successful if they are also specific about what tests to order. The ACR RA guidelines fail to specify this information, and there is ample evidence in the literature that nonhepatology and noninfectious disease clinicians frequently order HBV tests that are incomplete or simply incorrect, or misinterpret the results of those tests. ${ }^{19}$ A novel contribution of the study by Mohareb et $\mathrm{al}$ is the surprising finding that inappropriate $\mathrm{HBV}$ testing was quite common in the health system examined. ${ }^{6}$ This incomplete and inappropriate $\mathrm{HBV}$ testing likely reflects the complexity of $\mathrm{HBV}$ infection, which has different stages in individuals and over time. As shown in Table 1, rheumatologists require 3 tests ( $\mathrm{HBsAg}$, total $\mathrm{HBcAb}$, and $\mathrm{HBs} \mathrm{Ab}$ ) for a comprehensive assessment of a patient's HBV status and reactivation risk; this should be emphasized in guidelines as well as medical educational efforts. ${ }^{1,20}$ Importantly, these 3 tests can identify prior or resolved $\mathrm{HBV}$, which assumes clinical relevance in the setting of immunosuppression, and can identify patients in need of $\mathrm{HBV}$ vaccination. The inappropriate tests in Table 1 have minimal utility outside of the contexts of acute or chronic HBV, and thus should be discouraged in HBV screening efforts.

An important step in the implementation of these practice standards will be to demonstrate the cost-effectiveness of universal screening, which should be confirmed in future studies. Standard screening practices for HBV infection could avert costs associated with inappropriate HBV laboratory orders and the sequelae of HBV reactivation, including hepatitis or immunosuppression interruptions/switches.

\section{Improving health systems}

$\mathrm{HBV}$ screening is most likely to be effective when integrated in local health systems. There are several evidence-based strategies for doing so that could be adopted in diverse settings. One of the most powerful in the literature is the use of clinical decision support systems (CDSSs), which are defined as manual or electronic systems that "provide clinicians with patient-specific assessments or recommendations to aid clinical decision making.".21 CDSSs are usually implemented in the form of alerts, reminders, or order sets in the electronic health record (EHR) and are particularly suited to issues of drug safety. CDSSs have improved HBV screening rates prior to $\mathrm{b} / \mathrm{ts}$ DMARD administration in multiple studies by acting as safety checklists and helping clinicians with the ordering and interpretation of laboratory tests. ${ }^{22,23}$ Bullard et al reported on a multisite implementation of a CDSS in the US Veterans Health Administration system, in which new prescriptions for anti-CD20 monoclonal antibodies were linked with a helpful EHR alert that displayed a patient's prior laboratory results, highlighted deficiencies in HBV testing, and even integrated lab orders and subspecialty referrals. ${ }^{23}$ CDSSs can facilitate standardization of preimmunosuppression testing, reduce site- and provider-level heterogeneity, minimize inappropriate HBV testing, and facilitate treatment of patients newly diagnosed with $\mathrm{HBV}^{22,23}$

Physician-focused strategies are additional tools that have 
Table 1. Indicated and nonindicated tests for HBV screening prior to starting immunosuppression in individuals with rheumatic diseases.

\begin{tabular}{|c|c|c|c|}
\hline \multicolumn{2}{|r|}{ Indicated HBV Tests } & \multicolumn{2}{|r|}{ Nonindicated HBV Tests } \\
\hline Test & Description & Test & Description \\
\hline $\mathrm{HBsAg}$ & $\begin{array}{l}\text { Detects component of the HBV lipoprotein envelope } \\
\text { A hallmark of acute or chronic HBV, of which the latter } \\
\text { is characterized by the persistence of HBsAg > } 6 \text { months }\end{array}$ & HBV DNA & $\begin{array}{l}\text { Detects HBV DNA in blood and is thus a marker of } \\
\text { active viral replication } \\
\text {. Should not be tested in contexts other than acute HBV or } \\
\text { confirmed chronic HBV } \\
\text {. A negative HBV DNA result does not rule out chronic HBV }\end{array}$ \\
\hline \multirow[t]{2}{*}{$\mathrm{HBsAb}$} & $\begin{array}{l}\text { Detects antibodies to HBsAg that develop after either } \\
\text { natural infection or inoculation } \\
\text {. In most immunocompetent individuals, confers lifelong } \\
\text { immunity } \\
\text {. Can be positive or negative in those with prior or } \\
\text { resolved HBV } \\
\text {. In immunocompromised individuals with prior or resolved } \\
\text { HBV, the presence of HBsAb does not preclude HBV } \\
\text { reactivation }\end{array}$ & $\mathrm{HBeAg}$ & $\begin{array}{l}\text { Detects viral secretory protein that is associated with } \\
\text { HBV replication and infectivity in chronic HBV } \\
\text { Should not be tested in contexts other than confirmed } \\
\text { chronic HBV }\end{array}$ \\
\hline & & $\mathrm{HBeAb}$ & $\begin{array}{l}\text { Detects antibodies to } \mathrm{HBeAg} \text {, which are associated with } \\
\text { improvements in HBV DNA and liver disease in chronic } \\
\text { HBV } \\
\text {. Should not be tested in contexts other than confirmed } \\
\text { chronic HBV }\end{array}$ \\
\hline
\end{tabular}

HBV: hepatitis B virus; HBsAg: HBV surface antigen; HBcAb: HBV core antibody; HBsAb: HBV surface antibody; HBeAg: HBV e antigen; HBeAb: HBV e antibody.

been successfully implemented in projects to improve HBV screening rates. Prior research has suggested that the level of physician knowledge or familiarity with HBV is correlated with appropriate screening. ${ }^{11}$ In the study by Bullard et al, HBV screening improved from a rate of $60-70 \%$ to $>90 \%$, in part due to a coordinated physician education campaign that included seminars and online learning modules. ${ }^{23}$ These interventions were complemented by a feedback mechanism that provided clinics with their performance on HBV testing; this is an example of audit and feedback, another evidence-based strategy that allows clinicians to compare their performance to their peers or to professional standards. ${ }^{24}$ The Centers for Medicare \& Medicaid Services recently announced a new quality measure for US practices enrolled in the RISE registry that links appropriate $\mathrm{HBV}$ screening prior to $\mathrm{b} / \mathrm{tsDMARD}$ initiation with financial incentives, which could further motivate clinicians and practices to adhere to quality benchmarks.

Successful quality improvement (QI) integrates diverse disciplines and roles in the healthcare system. For instance, in the studies above that improved HBV testing prior to immunosuppressive therapy, appropriate hepatitis screening was adopted by pharmacists as a criterion for administration of anti-CD20 monoclonal antibodies; the projects also collaborated with hepatologists to facilitate timely consultation and triage of patients in need of antiviral therapy. ${ }^{22,23}$ The spectrum of HBV care potentially spans additional disciplines and roles in the healthcare system, including other subspecialties prescribing high-risk medications and infusion centers.

Successful QI efforts to improve drug safety, including HBV screening, have often combined several of the above strategies to optimize success. One novel approach to QI that could be applied to drug safety is the learning collaborative, in which shared quality improvement problems are tackled simultaneously by separate health systems under the guidance of content experts. ${ }^{25}$ Such learning collaboratives have led to demonstrable improvements in the care of juvenile idiopathic arthritis and $\mathrm{RA},{ }^{25}$ and could very well be critical to enhancing screening and drug safety across multiple healthcare systems.

\section{Conclusion}

In summary, the study by Mohareb et al reveals important gaps in the care of patients with rheumatic diseases initiating TCZ and TOF, with less than a third undergoing appropriate HBV testing, and a substantial number of patients tested with noninformative and nonindicated HBV tests. ${ }^{6}$ The study underscores the urgency of improving HBV testing in patients initiating immunosuppression; this can be achieved through various approaches to simplify and standardize screening practices. Rheumatologists should implement universal and appropriate HBV testing in patients starting immunosuppressive drugs. In addition, local 
health systems must monitor their preimmunosuppression care quality, and can use any combination of evidence-based approaches to improve substandard HBV screening.

\section{REFERENCES}

1. Koutsianas C, Thomas K, Vassilopoulos D. Reactivation of hepatitis $\mathrm{B}$ virus infection in rheumatic diseases: risk and management considerations. Ther Adv Musculoskelet Dis 2020;12:1759720X20912646.

2. Di Bisceglie AM, Lok AS, Martin P, Terrault N, Perrillo RP, Hoofnagle JH. Recent US Food and Drug Administration warnings on hepatitis B reactivation with immune-suppressing and anticancer drugs: just the tip of the iceberg? Hepatology 2015;61:703-11.

3. Polaris Observatory Collaborators. Global prevalence, treatment, and prevention of hepatitis B virus infection in 2016: a modelling study. Lancet Gastroenterol Hepatol 2018;3:383-403.

4. Le MH, Yeo YH, Cheung R, Henry L, Lok AS, Nguyen MH. Chronic hepatitis B prevalence among foreign-born and U.S.-born adults in the United States, 1999-2016. Hepatology 2020; 71:431-43.

5. Kim HS, Rotundo L, Yang JD, Kim D, Kothari N, Feurdean M, et al. Racial/ethnic disparities in the prevalence and awareness of Hepatitis B virus infection and immunity in the United States. J Viral Hepat 2017;24:1052-66.

6. Mohareb AM, Patel NJ, Fu X, Kim AY, Wallace ZS, Hyle EP. Screening for hepatitis $B$ virus prior to initiating tocilizumab and tofacitinib in patients with rheumatic diseases: a cross-sectional study. J Rheumatol 2022;49:104-9.

7. Chen YM, Huang WN, Wu YD, Lin CT, Chen YH, Chen DY, et al. Reactivation of hepatitis $\mathrm{B}$ virus infection in patients with rheumatoid arthritis receiving tofacitinib: a real-world study. Ann Rheum Dis 2018;77:780-2.

8. Kuo MH, Tseng CW, Lu MC, Tung CH, Tseng KC, Huang KY, et al. Risk of hepatitis $\mathrm{B}$ virus reactivation in rheumatoid arthritis patients undergoing tocilizumab-containing treatment. Dig Dis Sci 2021 Jan 2 (Epub ahead of print).

9. Schmajuk G, Li J, Evans M, Anastasiou C, Izadi Z, Kay JL, et al. RISE registry reveals potential gaps in medication safety for new users of biologics and targeted synthetic DMARDs. Semin Arthritis Rheum 2020;50:1542-8.

10. MacLachlan JH, Cowie BC. Hepatitis B virus epidemiology. Cold Spring Harb Perspect Med 2015;5:a021410.

11. Lai CJ, Nguyen TT, Hwang J, Stewart SL, Kwan A, McPhee SJ. Provider knowledge and practice regarding hepatitis B screening in Chinese-speaking patients. J Cancer Educ 2007;22:37-41.

12. Lee RSM, Bell CM, Singh JM, Hicks LK. Hepatitis B screening before chemotherapy: a survey of practitioners' knowledge, beliefs, and screening practices. J Oncol Pract 2012;8:325-8.
13. Visram A, Chan KKW, McGee P, Boro J, Hicks LK, Feld JJ. Poor recognition of risk factors for hepatitis $\mathrm{B}$ by physicians prescribing immunosuppressive therapy: a call for universal rather than risk-based screening. PloS One 2015;10:e0120749.

14. Fraenkel L, Bathon JM, England BR, St Clair EW, Arayssi T, Carandang K, et al. 2021 American College of Rheumatology guideline for the treatment of rheumatoid arthritis. Arthritis Rheumatol 2021;73:1108-23.

15. Saag KG, Teng GG, Patkar NM, Anuntiyo J, Finney C, Curtis JR, et al. American College of Rheumatology 2008 recommendations for the use of nonbiologic and biologic disease-modifying antirheumatic drugs in rheumatoid arthritis. Arthritis Rheum 2008;59:762-84.

16. Weinbaum CM, Williams I, Mast EE, Wang SA, Finelli L, Wasley A, et al. Recommendations for identification and public health management of persons with chronic hepatitis B virus infection. MMWR Recomm Rep 2008;57:1-20.

17. Terrault NA, Lok ASF, McMahon BJ, Chang KM, Hwang JP, Jonas $\mathrm{MM}$, et al. Update on prevention, diagnosis, and treatment of chronic hepatitis B: AASLD 2018 hepatitis B guidance. Hepatology 2018;67:1560-99.

18. Holroyd CR, Seth R, Bukhari M, Malaviya A, Holmes C, Curtis E, et al. The British Society for Rheumatology biologic DMARD safety guidelines in inflammatory arthritis. Rheumatol 2019; 58:e3-42.

19. Lawandi A, Cheng MP, Lee TC. Hepatitis B testing practices at a tertiary care centre and their associated costs: a retrospective analysis. PloS One 2019;14:e0219347.

20. Thio CL, Hawkins C. Hepatitis B Virus and Hepatitis Delta Virus. Mandell, Douglas, and Bennett's principles and practice of infectious diseases 8th ed. Elsevier; 2015:1815-39.

21. Kawamoto K, Houlihan CA, Balas EA, Lobach DF. Improving clinical practice using clinical decision support systems: a systematic review of trials to identify features critical to success. BMJ 2005;330:765.

22. Sampedro B, Hernández-López C, Ferrandiz JR, Illaro A, Fábrega E, Cuadrado A, et al. Computerized physician order entry-based system to prevent $\mathrm{HBV}$ reactivation in patients treated with biologic agents: the PRESCRIB project. Hepatology 2014;60:106-13.

23. Bullard AJ, Cunningham FE, Volpp BD, Lowy E, Beste LA, Heron $\mathrm{BB}$, et al. Preventing hepatitis $\mathrm{B}$ reactivation during anti-CD20 antibody treatment in the Veterans Health Administration. Hepatol Commun 2018;2:1136-46.

24. Ivers N, Jamtvedt G, Flottorp S, Young JM, Odgaard-Jensen J, French SD, et al. Audit and feedback: effects on professional practice and healthcare outcomes. Cochrane Database Syst Rev 2012; CD000259.

25. Liu LH, Choden S, Yazdany J. Quality improvement initiatives in rheumatology: an integrative review of the last 5 years. Curr Opin Rheumatol 2019;31:98-108. 